\title{
Loss of islet sympathetic nerves and impairment of glucagon secretion in the NOD mouse: relationship to invasive insulitis
}

\author{
G. J. Taborsky Jr • Q. Mei • D. J. Hackney • \\ D. P. Figlewicz $・$ R. LeBoeuf • T. O. Mundinger
}

Received: 8 June 2009 / Accepted: 6 July 2009 /Published online: 2 October 2009

(C) Springer-Verlag 2009

\begin{abstract}
Aims/hypothesis We hypothesised that non-obese diabetic mice (NOD) mice have an autoimmune-mediated loss of islet sympathetic nerves and an impairment of sympathetically mediated glucagon responses. We aimed: (1) to determine whether diabetic NOD mice have an early impairment of the glucagon response to insulin-induced hypoglycaemia (IIH) and a coincident loss of islet sympathetic nerves; (2) to determine whether invasive insulitis is required for this nerve loss; and (3) to determine whether sympathetically mediated glucagon responses are also impaired.

Methods We measured glucagon responses to both IIH and tyramine in anaesthetised mice. We used immunohistochemistry to quantify islet sympathetic nerves and invasive insulitis. Results The glucagon response to IIH was markedly impaired in NOD mice after only 3 weeks of diabetes (change, $-70 \%$ ). Sympathetic nerve area within the islet was also markedly reduced at this time (change, $-66 \%$ ). This islet nerve loss was proportional to the degree of invasive insulitis. More
\end{abstract}

G. J. Taborsky $\operatorname{Jr}(\bowtie) \cdot$ Q. Mei • D. J. Hackney • D. P. Figlewicz •

T. O. Mundinger

Division of Endocrinology/Metabolism (S-151),

Veterans Affairs Puget Sound Health Care System,

1660 S. Columbian Way,

Seattle, WA 98108, USA

e-mail: taborsky@u.washington.edu

G. J. Taborsky Jr • Q. Mei · D. J. Hackney • R. LeBoeuf •

T. O. Mundinger

Department of Medicine, University of Washington,

Seattle, WA, USA

D. P. Figlewicz

Department of Psychiatry and Behavioral Sciences,

University of Washington,

Seattle, WA, USA importantly, blocking the infiltration prevented the nerve loss. Mice with autoimmune diabetes had an impaired glucagon response to sympathetic nerve activation, whereas those with non-autoimmune diabetes did not.

Conclusions/interpretation The invasive insulitis seen in diabetic NOD mice causes early sympathetic islet neuropathy. Further studies are needed to confirm that early sympathetic islet neuropathy is responsible for the impaired glucagon response to tyramine.

Keywords Alloxan · Diabetes · 6-Hydroxydopamine . Hypoglycaemia · Lymphocytes · Neuropathy · NOD mice · Tyramine
Abbreviations
CFA Complete Freund's adjuvant
eSIN Early sympathetic islet neuropathy
IIH Insulin-induced hypoglycaemia
NPY Neuropeptide Y

\section{Introduction}

In humans, the glucagon response to insulin-induced hypoglycaemia (IIH) is impaired soon after the onset of type 1 diabetes [1], and it remains markedly impaired even when antecedent hypoglycaemia is meticulously avoided $[2,3]$. These data suggest that this particular impairment is caused by irreversible anatomical defects, like the loss of islet beta cells and islet sympathetic nerves, as opposed to reversible physiological adaptations, like hypoglycaemiaassociated autonomic failure [4].

Studies in streptozotocin diabetic rats confirm that the loss of islet beta cells is one anatomical defect that 
contributes to the impaired glucagon response to IIH. However, the magnitude of the beta cell contribution varies across studies. Some find that beta cell destruction per se completely abolishes the glucagon response to IIH $[5,6]$ while others find that most of the glucagon response remains [7-9]. We favour the concept that beta cell loss accounts for some, but not all, of the glucagon impairment because the autonomic nervous system, a known stimulator of glucagon secretion [10], is still fully activated by IIH early in streptozotocin diabetes $[5,7,11]$. Therefore, we focused on the autonomic nervous system when looking for a second anatomical impairment in autoimmune diabetes.

Late impairments in two of the three autonomic inputs to the islet, the parasympathetic nerves and adrenal medullary adrenaline (epinephrine), have been reported during IIH in type 1 diabetes. However, early after diabetes onset, parasympathetic activation during IIH is normal, and the latter impairment is correlated to the duration of illness [12] and is generally attributed to the presence of diabetic autonomic neuropathy. Likewise, early in conventionally controlled diabetes, the adrenaline response is normal if hypoglycaemia-associated autonomic failure is avoided [13]. Furthermore, the early impairment of the glucagon response to IIH in type 1 diabetic patients does not correlate with impaired adrenaline or parasympathetic responses [14]. Therefore, we looked for an anatomical impairment of the third autonomic input, the islet sympathetic nerves, because preventing the activation of islet sympathetic nerves during IIH markedly impairs the glucagon response, at least in non-diabetic animals [15]. When we analysed the sympathetic nerves of the BB diabetic rat, an animal model with severe autoimmune diabetes [16], we found both an early, selective and marked loss of their islet sympathetic nerve terminals [17] and an impairment of their glucagon response to selective sympathetic nerve stimulation [18]. We named this syndrome early sympathetic islet neuropathy (eSIN) to distinguish it from diabetic autonomic neuropathy.

However, there are significant differences in the onset, severity and progression of diabetes in the $\mathrm{BB}$ rat compared with the human form of the disease. In contrast, there is some similarity in these three phenotypes between nonobese diabetic mice (NOD) mice and humans with type 1 diabetes. With regard to diabetes onset, it is very abrupt in the $\mathrm{BB}$ rat [16], with none of the long preclinical period that characterises type 1 diabetes in the NOD mouse [19] and in most humans [20]. With regard to diabetes severity, islet beta cell loss is nearly complete at diabetes onset in BB rats [16], in contrast to that of NOD mice [21, 22] and humans, $[23,24]$ in both of which there is evidence for residual beta cell function early in diabetes. With regard to diabetes progression, both NOD mice [25] and humans [24] have a progressive loss of residual beta cell mass and function with increasing duration of type 1 diabetes.
It was not known whether diabetic NOD mice had an early impairment of the glucagon response to IIH. Therefore, in our first study we sought to demonstrate such an impairment, thereby establishing a rationale for examining diabetic NOD mice for the presence and cause of eSIN. Our subsequent studies were not designed to determine the mediators of that impaired glucagon response to $\mathrm{IIH}$; rather, we sought to determine (1) whether eSIN was present in the diabetic NOD mouse, (2) whether eSIN was caused by the lymphocytic infiltration of the islet, and (3) whether the glucagon response to sympathetic neural activation was impaired.

\section{Methods}

Animals and pretreatments Female NOD mice (The Jackson Laboratory, Bar Harbor, ME, USA) were studied. In some experimental groups (see Table 1), the onset of autoimmune diabetes was induced/accelerated by the injection of cyclophosphamide (300 mg/kg i.p.; Sigma, St Louis, MO, USA) given at age 8-9 weeks. Cyclophosphamide-induced diabetes was confirmed 2-3 weeks after cyclophosphamide injection. In other experimental groups, autoimmune diabetes was allowed to develop naturally between 13 and 30 weeks of age. Cyclophosphamide and naturally occurring diabetes in NOD mice were treated with insulin pellets for 3-5 weeks (Linbit, $\sim 0.1 \mathrm{U} /$ day; Linshin, Scarborough, ON, Canada).

To block the invasive insulitis that causes the development of diabetes [26], one group of cyclophosphamide-treated NOD mice received an injection of complete Freund's adjuvant (CFA, $0.05 \mathrm{ml}$ emulsion; Sigma) into the left hind footpad 1 day after cyclophosphamide injection [27]. Swelling of the hindlimb, observed the following day and persisting throughout the study, confirmed successful injection of CFA.

Female non-obese diabetes-resistant mice (NOR; The Jackson Laboratory) were pretreated with either the pancreatic beta cell toxin alloxan $(180 \mathrm{mg} / \mathrm{kg}$ s.c. in saline; Sigma), to induce non-autoimmune diabetes in the absence of nerve loss, or the sympathetic neurotoxin 6hydroxydopamine $(200 \mathrm{mg} / \mathrm{kg}$ i.v., $4 \%$ ascorbic acid in saline; Sigma), to destroy islet sympathetic nerves in the absence of diabetes.

Research involving animals was conducted in a facility accredited by the Association for Assessment and Accreditation of Laboratory Animal Care International, all protocols were approved by the Institutional Animal Care and Use Committee of the Seattle VA Puget Sound Health Care System, and all mice included in these studies were certified as healthy by the Veterinary Medical Officer.

Insulin-induced hypoglycaemia Cyclophosphamide diabetic and non-diabetic NOD mice were anaesthetised with 
isoflurane (1.5-2.0\%) and placed on a self-regulating heating pad (Harvard Apparatus; Holliston, MA, USA) to maintain body temperature at $37^{\circ} \mathrm{C}$. Through a midline laparotomy, both the portal vein and the inferior vena cava were catheterised for blood sampling (PE 10; Beckton Dickinson, Sparks, MD, USA), with the tip of the portal catheter advanced to the hilus of the liver to access glucagon-rich blood. The right common jugular vein was catheterised for drug and donor blood infusion. A $45 \mathrm{~min}$ stabilisation period preceded baseline blood sampling.

Blood glucose was monitored from the inferior vena cava $(1 \mu 1$ blood; OneTouch Ultra 2 blood glucose meter; LifeScan, Milpitas, CA, USA) at regular intervals before and during insulin-induced hypoglycaemia (IIH). An infusion of soluble insulin $\left(20 \mathrm{mU} \mathrm{kg}{ }^{-1} \mathrm{~min}^{-1}\right.$ i.v. $)$ and variable glucose (14-43 mg kg-1 $\min ^{-1}$ i.v.) was started, in diabetic mice only, $20 \mathrm{~min}$ into the stabilisation period to achieve baseline glucose levels similar to those of nondiabetic controls. A baseline blood sample was then drawn from the portal vein for later measurement of plasma glucose, glucagon and adrenaline concentrations, using assay methods described previously [18]. The volume of all portal vein blood samples was fully replaced by a concomitant jugular vein infusion of heparinised donor blood. After the baseline sample had been drawn, a bolus of regular insulin was given ( $3 \mathrm{U} / \mathrm{kg}$ i.v.), and the insulin/ variable glucose infusion in the diabetic mice was discontinued. A second, 'stimulated' blood sample was drawn from the portal vein $5 \mathrm{~min}$ after the glucose nadir had been reached. Because the goal of the hypoglycaemia protocol was to achieve a glucose nadir of $2.2 \mathrm{mmol} / \mathrm{l}$ in portal venous plasma, mice achieving a nadir above $2.8 \mathrm{mmol} / \mathrm{l}$ or below $1.7 \mathrm{mmol} / \mathrm{l}$ were omitted from the study.

Sympathetic neural activation The experimental preparation for studying glucagon responses to the sympathomimetic tyramine $\left(1,280 \mu \mathrm{g} \mathrm{kg}^{-1} \mathrm{~min}^{-1}\right.$ for 5 min i.v.; Sigma), was similar to that for the IIH study but with three exceptions. First, diabetic NOD mice remained hyperglycaemic throughout the experiment. Second, an inferior vena cava sampling catheter was not implanted. Third, a third (recovery) portal vein blood sample was drawn $15 \mathrm{~min}$ after discontinuation of the tyramine infusion.

Tissue fixation and immunohistochemistry Mouse pancreatic tissue was fixed, harvested, sectioned and mounted by a method we have previously used in rats [17]. Four $16 \mu \mathrm{m}$ sections per mouse pancreas, each separated by $160 \mu \mathrm{m}$, were incubated with polyclonal antibody to neuropeptide $\mathrm{Y}$ (NPY; 1:1,000, B 54-1; Accurate Chemical and Scientific, Westbury, NY, USA) and with monoclonal glucagon antibody (1:1,000, G2654 Clone K 79; Sigma). The second antibodies for glucagon and NPY were Alexa Fluor 488congugated goat anti-mouse antibody (1:200, A-11029; Molecular Probes, Invitrogen, Carlsbad, CA, USA) and $\mathrm{Cy}^{3}$ (fluorescent cyanine dye)-conjugated sheep anti-rabbit antibody (1:200, 705-165-147; Jackson Immunoresearch Labs, West Grove, PA, USA), respectively. Slides were mounted with medium containing Hoechst staining solution (Sigma) to assess invasive insulitis, which was verified by haematoxylin and eosin staining in selected cases.

Quantification Ten islets per mouse, a sample size sufficient to detect a $35 \%$ decrease in islet sympathetic nerves (see Results), were randomly chosen for measurement of islet size, percentage of islet area infiltrated by lymphocytes, islet sympathetic nerve area and, in selected cases, islet glucagon area. The perimeter of the islet was traced, and total islet area was calculated using a computer-assisted image analysis system. The area of lymphocytic infiltration was identified by Hoechst staining and was calculated by subtracting the islet area clear of lymphocytic infiltration from the total islet area. The islet area occupied by alpha cells was identified by glucagon staining and quantified by circumscribing the staining for computer calculation of glucagon area. Sympathetic nerve fibres within the islet were identified by NPY immunostaining and quantified by tracing each fibre segment within an islet image using a computer (arrows in Fig. 2a) to obtain the cumulative area of NPY-positive nerve fibres $\left(\mu \mathrm{m}^{2} /\right.$ islet $)$, as we have done previously for islet sympathetic nerves of BB and Wistar rats [17, 18].

Statistical analysis When comparing data across three groups, we used analysis of variance and a post hoc Dunnett test. When making comparisons between two groups, we used a two-sample $t$ test. The line relating islet infiltration to islet NPY fibre area was generated using standard linear regression. All data are expressed as mean \pm SEM.

\section{Results}

Glucagon response to insulin-induced hypoglycaemia We first sought to determine whether diabetic NOD mice had an early impairment of their glucagon response to IIH. Cyclophosphamide-induced, 3 week diabetic NOD mice and non-diabetic controls had similar baseline glucagon values ( $81 \pm 5 \mathrm{ng} / \mathrm{l}$ and $87 \pm 10 \mathrm{ng} / \mathrm{l}$, respectively), yet the portal vein glucagon response to IIH was markedly impaired in the diabetic NOD mice (change, $-70 \%$; $p<0.03$; Fig. 1b). In contrast, the basal plasma glucose levels in the two groups were similar and the nadirs were identical $(2.2 \mathrm{mmol} / \mathrm{l}$; Fig. 1a). In addition, the basal plasma adrenaline levels and the responses to IIH were similar (Fig. 1c). 
Table 1 Effect of autoimmune vs non-autoimmune diabetes on islet innervation and infiltration

\begin{tabular}{|c|c|c|c|c|c|c|c|}
\hline Mouse strain & Diabetic phenotype & $\begin{array}{l}\text { Duration of type } 1 \\
\text { diabetes (weeks) }\end{array}$ & Age (weeks) & $n$ & $\begin{array}{l}\text { Islet nerves } \\
\left(\mu \mathrm{m}^{2} \mathrm{NPY} / \text { islet }\right)\end{array}$ & $\begin{array}{l}\text { Islet infiltration } \\
\text { (\% of islet area) }\end{array}$ & $\begin{array}{l}\text { Islet area } \\
\left(\mu \mathrm{m}^{2} \times 10^{3}\right)\end{array}$ \\
\hline NOD & Non-diabetic & - & $12 \pm 1$ & 10 & $116 \pm 7$ & $34 \pm 4$ & $51 \pm 4$ \\
\hline NOD & $\begin{array}{l}\text { Type } 1 \text { diabetes } \\
\text { (cyclophosphamide) }\end{array}$ & 3 & $14 \pm 1$ & 7 & $39 \pm 8^{\mathrm{b}, \mathrm{d}}$ & $52 \pm 13$ & $42 \pm 11$ \\
\hline NOD & Non-diabetic (CFA) & - & $13 \pm 1$ & 7 & $137 \pm 13^{\mathrm{f}}$ & $16 \pm 5^{\mathrm{e}}$ & $54 \pm 10$ \\
\hline NOD & Non-diabetic & - & $24 \pm 2$ & 8 & $91 \pm 13$ & $27 \pm 6$ & $40 \pm 7$ \\
\hline NOD & Type 1 diabetes (natural) & 3 & $22 \pm 1$ & 9 & $63 \pm 7^{\mathrm{a}}$ & $41 \pm 6$ & $44 \pm 7$ \\
\hline NOD & Type 1 diabetes (natural) & 5 & $26 \pm 2$ & 7 & $26 \pm 4^{\mathrm{b}, \mathrm{d}}$ & $59 \pm 9^{\mathrm{a}}$ & $31 \pm 7$ \\
\hline NOR & Non-diabetic & - & $27 \pm 1$ & 5 & $126 \pm 7$ & $15 \pm 8$ & $47 \pm 8$ \\
\hline NOR & Type 1 diabetes (alloxan) & 5 & $26 \pm 1$ & 6 & $112 \pm 10$ & $5 \pm 2$ & $16 \pm 3^{\mathrm{c}}$ \\
\hline
\end{tabular}

Data are mean \pm SEM (except duration of diabetes)

Significantly different from respective non-diabetic control: ${ }^{\mathrm{a}} p<0.05 ;{ }^{\mathrm{b}} p<0.01 ;{ }^{\mathrm{c}} p<0.0025$

Significantly different from type 1 diabetes (natural), 3 weeks: ${ }^{\mathrm{d}} p<0.005$

Significantly different from type 1 diabetes (cyclophosphamide), 3 weeks: ${ }^{\mathrm{e}} p<0.01 ;{ }^{\mathrm{f}} p<0.00005$

Islet nerve loss and invasive insulitis We next sought to determine whether there was a defect in islet sympathetic innervation in cyclophosphamide-treated, 3-week diabetic NOD mice (Fig. 2a and b). NPY-positive nerve fibre area in the islets of these mice was markedly less than that in their age and sex-matched non-diabetic NOD controls (change, $-66 \%$; $p<0.01$; Fig. 2c and Table 1). To determine whether cyclophosphamide treatment had accelerated the loss of islet sympathetic nerves, we compared this nerve loss with that in NOD mice that became diabetic naturally but had the same duration of diabetes (3 weeks). There was only one-half the nerve loss in the group with naturally occurring diabetes when compared with their own controls (change, $-31 \%$; $p<$ 0.05; Fig. $2 \mathrm{~d}$ and Table 1). To determine whether islet nerve loss progressed with the duration of diabetes, we measured the loss of islet sympathetic nerves in NOD mice with 5 weeks of naturally occurring diabetes. The nerve loss in this 5 week group was double that in the group with 3 weeks of naturally occurring diabetes (change, $-71 \% ; p<0.01$;
Fig. 2d and Table 1). With regard to invasive insulitis, the percentage of islet area infiltrated in either cyclophosphamide diabetic or natural diabetic NOD mice of 3 weeks duration tended to be larger than in their respective nondiabetic controls (Fig. 3e, f and Table 1). This tendency reached significance after 5 weeks of naturally occurring diabetes $(p<0.05$; Fig. $3 \mathrm{f}$ and Table 1$)$.

To determine whether invasive insulitis, in the absence of diabetes, was associated with islet nerve loss, we stratified the 92 islets from non-diabetic NOD control mice, based on infiltration. In the heavily infiltrated group $(>50 \%$ of islet area infiltrated, $n=23$ islets), infiltration averaged $76 \pm 3 \%$ of islet area, whereas it averaged only $10 \pm 2 \%$ in the lightly infiltrated group ( $<50 \%$ of islet area infiltrated, $n=69$ islets). Importantly, the heavily infiltrated group had one-half the area of NPY-positive fibres in their islets $\left(50 \pm 10 \mu \mathrm{m}^{2} /\right.$ islet $)$ of the lightly infiltrated group ( $99 \pm 11 \mu \mathrm{m}^{2} /$ islet; $\left.p<0.01\right)$.

We then determined whether diabetes, in the absence of invasive insulitis, was associated with islet nerve loss.
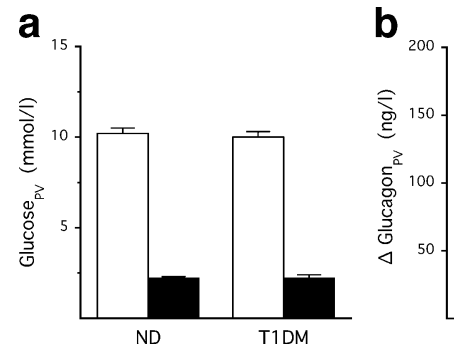

Fig. 1 Impaired glucagon response to insulin-induced hypoglycaemia in diabetic NOD mice. a The hypoglycaemic nadir in portal vein (PV) plasma achieved during insulin-induced hypoglycaemia (black columns) in cyclophosphamide-diabetic NOD mice (type 1 diabetes mellitus [T1DM]; duration of diabetes, 3 weeks) and their age- and sex-matched non-diabetic controls (ND). Baseline glucose levels in the two groups (white columns) are similar because a low dose of insulin was infused,

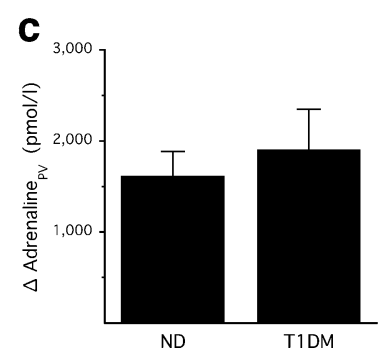

in type 1 diabetes mellitus only, before baseline sampling (see the Methods). b Portal vein glucagon responses $(\Delta)$ to insulin-induced hypoglycaemia in type 1 diabetes mellitus and non-diabetic controls. $\mathbf{c}$ Portal vein adrenaline responses $(\Delta)$ to hypoglycaemia, an index of general autonomic activation. Data are mean \pm SEM. Significant difference compared with non-diabetic controls: $\uparrow p<0.03$ 
Fig. 2 Loss of islet sympathetic nerves in autoimmune diabetic NOD mice. a Staining of NPY in sympathetic nerve fibres within an islet of a non-diabetic NOD mouse (dashed line indicates islet boundary). The characteristic punctate morphology of peripheral sympathetic nerves is evident (arrows). b Neural NPY staining within an islet of an NOD mouse with cyclophosphamide-induced diabetes (duration of diabetes, 3 weeks). c Islet nerve fibre area in cyclophosphamide diabetic NOD mice (T1DM, type 1 diabetes mellitus; duration of diabetes, 3 weeks) and their age- and sex-matched non-diabetic NOD controls (ND). d Islet nerve fibre area after 3 weeks and 5 weeks of naturally occurring diabetes in NOD mice (T1DM 3 weeks and 5 weeks, respectively) compared with their own age- and sex-matched non-diabetic controls (ND). Significant difference compared with non-diabetic controls: ${ }^{*} p<0.05,{ }^{*} p<0.01$. Significant difference compared with 3 weeks of type 1 diabetes mellitus: ${ }^{\dagger} p<0.01$

Although the non-diabetic NOR mice had the expected peri-insulitis, invasive insulitis was minimal (Table 1) and was not increased after 5 weeks of alloxan diabetes (Table 1). Importantly, there was no significant decrease in NPYpositive nerve area in the islets of alloxan-diabetic NOR mice (Table 1). Thus invasive insulitis, but not diabetes, was associated with loss of islet sympathetic nerves.

To prove that invasive insulitis was required for the loss of islet sympathetic nerves, we used CFA to block the invasive insulitis normally induced by cyclophosphamide [27]. Islet infiltration in CFA-treated, cyclophosphamidenon-diabetic NOD mice was markedly lower than that in cyclophosphamide-diabetic NOD mice $(p<0.01$; Fig. $4 \mathrm{a}$ and Table 1). Importantly, the area of islet NPY-positive nerve fibres in the CFA-treated non-diabetic mice was markedly higher than that in cyclophosphamide-diabetic NOD mice $(p<0.00005$; Fig. $4 \mathrm{~b}$ and Table 1$)$.

To determine whether invasive insulitis was the major determinant of the islet nerve loss, we correlated these two variables across all 49 mice and across all seven groups used in this study. As expected, there was a highly significant negative linear correlation between the amount of infiltration and the area of NPY-positive fibres within the islet across mice $(p<0.00001 ; r=-0.582$; Fig. 5a). However, in this analysis, islet infiltration accounted for only $34 \%$ of the variance in the islet NPY-positive nerve area, suggesting either a second major determinant of islet nerve area or significant random error in our estimates of islet nerve area. We reduced the random error by averaging the islet NPYpositive nerve area (and islet infiltration) for each of the seven groups used in the study. The striking improvement in the correlation coefficient $(r=-0.944$; Fig. $5 b)$ indicated that islet infiltration now accounted for nearly $90 \%$ of the variance of islet NPY-positive nerve area.

Glucagon responses to sympathetic neural activation We next determined whether there was an impaired glucagon response to selective activation of sympathetic nerves in those diabetic NOD mice that had the smallest amount of nerve loss (3 weeks of naturally occurring diabetes). In

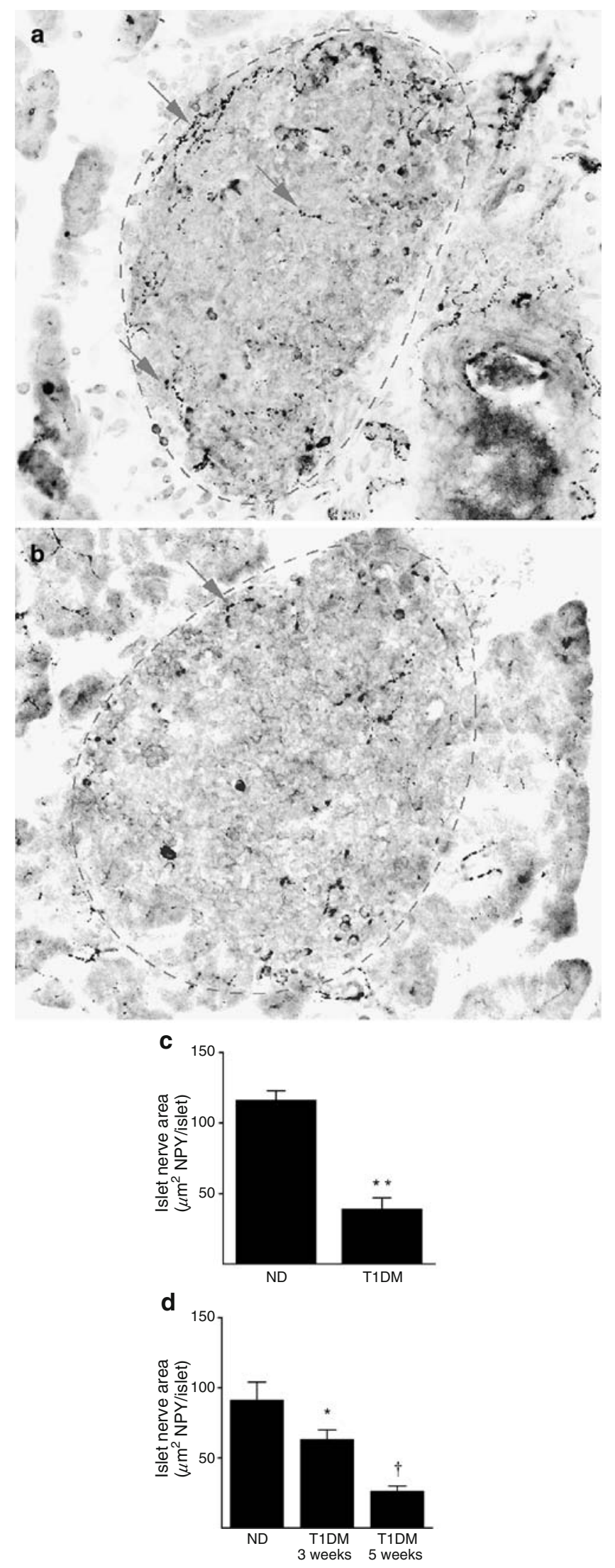



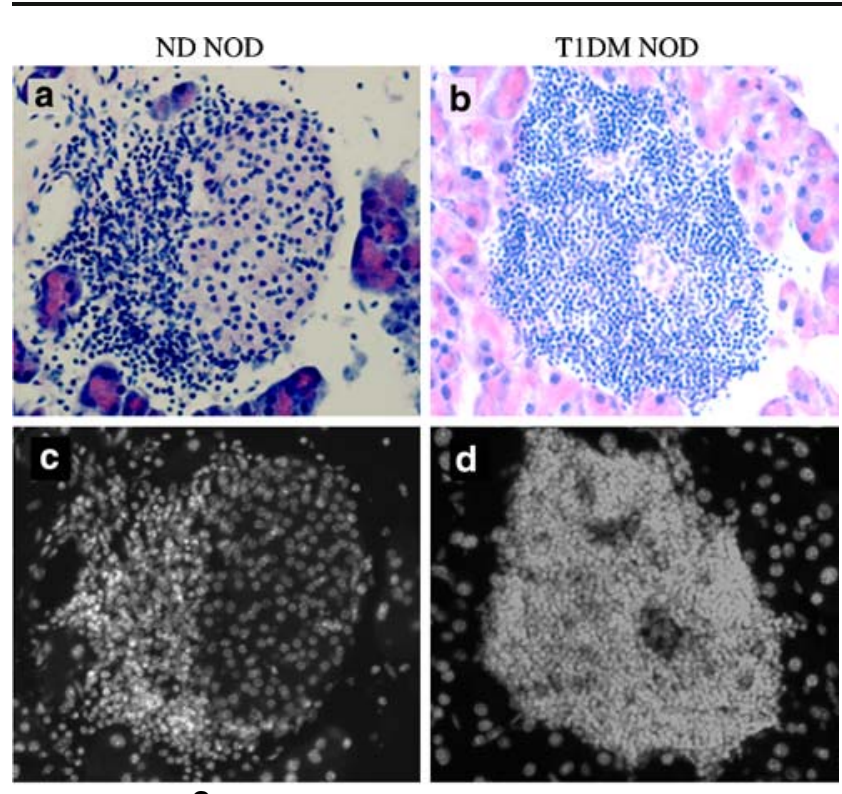

$\mathbf{e}$

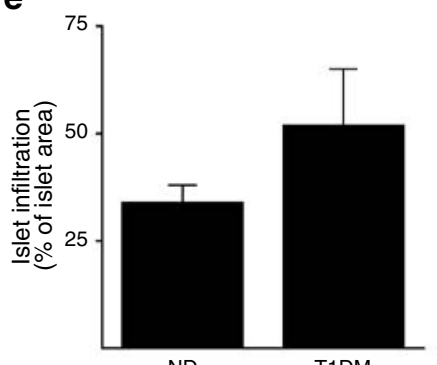

$\mathbf{f}$

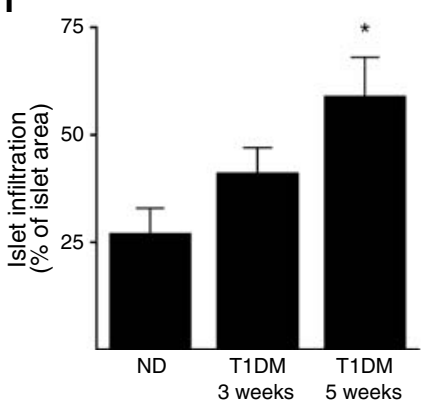

Fig. 3 Increased invasive insulitis in islets of diabetic NOD mice. Infiltration of presumed lymphocytes into an islet of a non-diabetic NOD mouse (ND), as demonstrated by haematoxylin-eosin staining (a) and fluorescent Hoechst staining (c). Heavier infiltration of an islet from a naturally occurring diabetic NOD mouse (T1DM, type 1 diabetes mellitus; duration of diabetes, 5 weeks), as demonstrated by haematoxylin-eosin staining (b) and Hoechst staining (d). e Degree of islet infiltration in cyclophosphamide-diabetic NOD mice (T1DM; duration of diabetes, 3 weeks) and their age- and sex-matched nondiabetic controls (ND), as determined by Hoechst staining. f Islet infiltration in NOD mice after 3 weeks and 5 weeks of naturally occurring diabetes (T1DM; 3 weeks and 5 weeks) compared with their own age- and sex-matched non-diabetic controls (ND). Significant difference compared with non-diabetic controls: ${ }^{*} p<0.05$

non-diabetic NOD mice, tyramine increased portal venous noradrenaline (norepinephrine) (Table 2) and glucagon (Fig. 6a and Table 2) concentrations. The plasma noradrenaline response to tyramine in NOD mice with 3 weeks of
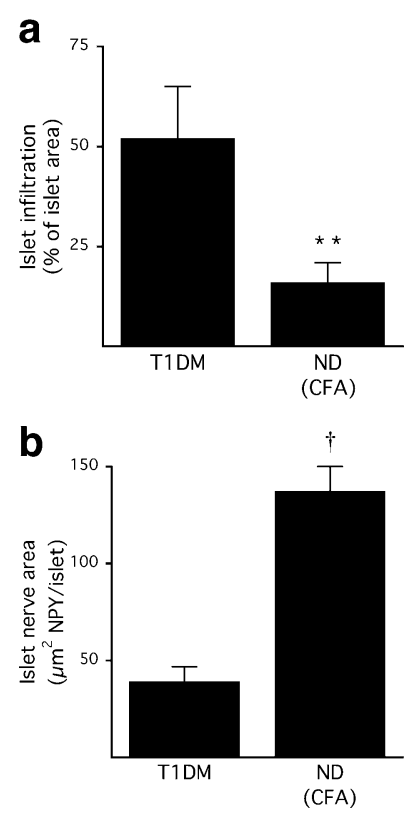

Fig. 4 Blocking invasive insulitis prevents the loss of islet sympathetic nerves. a Effect of CFA, given to NOD mice 1 day after cyclophosphamide administration, in blocking the usual islet infiltration and development of diabetes seen when NOD mice are given cyclophosphamide alone (T1DM, type 1 diabetes mellitus; duration of diabetes, 3 weeks). b Effect of CFA on the islet nerve loss seen in T1DM. Significantly different from T1DM: $* * p<0.01,{ }^{\dagger} p<0.00005$
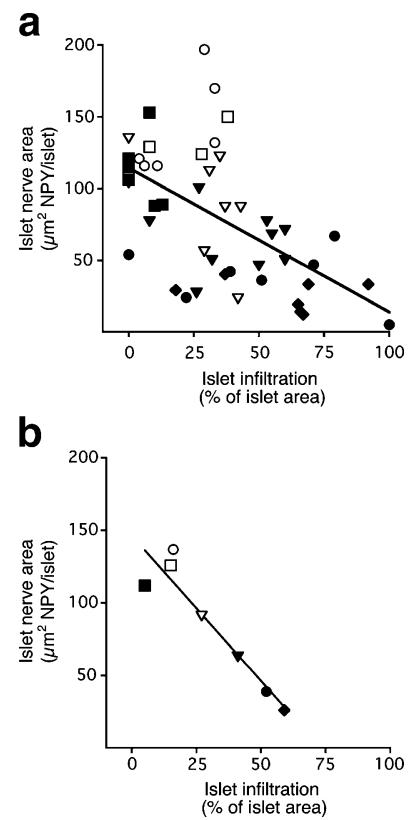

Fig. 5 Islet infiltration is associated with islet nerve loss. Islet nerve area is represented as area of NPY-positive fibres per islet. A negative relationship between islet infiltration and islet nerve area, as seen in 49 individual mice (a) and in the averages of seven groups (b). White circles, non-diabetic (cyclophosphamide/CFA); black circles, type 1 diabetes (cyclophosphamide), inverted white triangles, non-diabetic (natural); inverted black triangles, type 1 diabetes (natural, 3 weeks); black diamonds, type 1 diabetes (natural, 5 weeks); white squares, nondiabetic (NOR); black squares, type 1 diabetes (NOR alloxan). a $r=$ $-0.582 ; p<0.00001 ; n=49$ mice. b $r=-0.944 ; p<0.001 ; n=7$ groups 
Table 2 Effect of autoimmune vs non-autoimmune diabetes on glucagon responses to activation of sympathetic nerves

\begin{tabular}{|c|c|c|c|c|c|c|c|c|c|c|c|}
\hline \multirow{2}{*}{$\begin{array}{l}\text { Mouse } \\
\text { strain }\end{array}$} & \multirow{2}{*}{$\begin{array}{l}\text { Diabetic } \\
\text { phenotype }\end{array}$} & \multirow{2}{*}{$\begin{array}{l}\text { Age } \\
\text { (weeks) }\end{array}$} & \multirow[t]{2}{*}{$n$} & \multicolumn{4}{|c|}{ Glucagon (ng/l) } & \multicolumn{4}{|c|}{ Noradrenaline (nmol/1) } \\
\hline & & & & Basal & TYR & Recovery & $\Delta \mathrm{TYR}$ & Basal & TYR & Recovery & $\Delta \mathrm{TYR}$ \\
\hline NOD & Non-diabetic & $18 \pm 1$ & 12 & $104 \pm 7$ & $364 \pm 32$ & $112 \pm 6$ & $+260 \pm 32$ & $5.7 \pm 0.6$ & $14.2 \pm 1.4$ & $4.1 \pm 0.4$ & $+8.4 \pm 1.3$ \\
\hline NOD & $\mathrm{T}_{1} \mathrm{D}^{\mathrm{d}}$ (natural) & $21 \pm 1$ & 16 & $101 \pm 15$ & $246 \pm 27$ & $93 \pm 12$ & $+145 \pm 23^{\mathrm{a}}$ & $8.3 \pm 0.7$ & $15.7 \pm 1.3$ & $6.7 \pm 0.6$ & $+7.4 \pm 1.0$ \\
\hline NOR & Non-diabetic & $13 \pm 1$ & 9 & $96 \pm 9$ & $266 \pm 31$ & $118 \pm 14$ & $+170 \pm 24$ & $5.4 \pm 0.4$ & $17.1 \pm 0.9$ & $6.2 \pm 0.5$ & $+11.7 \pm 0.7$ \\
\hline NOR & $\mathrm{T}_{1} \mathrm{D}^{\mathrm{d}}$ (alloxan) & $14 \pm 1$ & 11 & $85 \pm 7$ & $275 \pm 31$ & $106 \pm 10$ & $+191 \pm 26$ & $5.0 \pm 0.3$ & $15.5 \pm 1.0$ & $5.8 \pm 0.4$ & $+10.5 \pm 0.7$ \\
\hline NOR & $\begin{array}{l}\text { Non-diabetic } \\
\text { (6-OHDA) }\end{array}$ & $13 \pm 1$ & 8 & $92 \pm 8$ & $127 \pm 13$ & $139 \pm 39$ & $+35 \pm 11^{\mathrm{b}}$ & $3.5 \pm 0.3$ & $3.9 \pm 0.2$ & $2.7 \pm 0.3$ & $+0.4 \pm 0.2$ \\
\hline
\end{tabular}

Data are mean \pm SEM (except duration of diabetes)

Significantly different from respective non-diabetic control: ${ }^{\mathrm{a}} p<0.005 ;{ }^{\mathrm{b}} p<0.0001 ;{ }^{\mathrm{c}} p<0.00001$

${ }^{\mathrm{d}}$ Duration of diabetes: 3 weeks

$\Delta$, Change from basal; 6-OHDA, 6-hydroxydopamine; T1D, type 1 diabetes; TYR, tyramine

naturally occurring diabetes was similar to that in nondiabetic controls (Table 2); however, the plasma glucagon response in the diabetic mice was, as expected, significantly smaller (change, $-44 \%$; $p<0.005$; Fig. 6a and Table 2). These diabetic mice had a significant loss of islet sympathetic nerves (see above) but their islet glucagon area $\left(4,932 \pm 665 \mu \mathrm{m}^{2}\right.$ or $19 \pm 6 \%$ of islet area) was not significantly different from that of their non-diabetic NOD controls $\left(4,117 \pm 805 \mu \mathrm{m}^{2}\right.$ or $13+3 \%$ of islet area).

In contrast to mice with autoimmune NOD diabetes, NOR mice with alloxan-induced diabetes had a plasma glucagon response to tyramine that was not impaired compared with their age- and sex-matched controls (change, $+12 \%$; Fig. $6 \mathrm{~b}$ and Table 2), consistent with their retention of islet sympathetic nerves (see above). NOR mice treated with 6-hydroxydopamine had a marked reduction of both the plasma noradrenaline and the glucagon response to tyramine compared with NOR controls (change, $-96 \%$ and $-79 \%$, respectively; Fig. $6 \mathrm{~b}$ and Table 2).

\section{Discussion}

We first tested for and found a marked impairment of the glucagon response to IIH in diabetic NOD mice to which multiple anatomical defects within the islet might contribute. This impairment is unlikely to be due to the anaesthesia and surgery used in our study because both the basal glucagon levels and the response to IIH in our non-diabetic controls were similar to those reported in conscious mice $[28,29]$. Our novel demonstration of an impaired glucagon response to IIH in diabetic NOD mice, coupled with those already published in BB diabetic rats [30] and in humans with type 1 diabetes [31,32], makes it clear that an early impairment of the glucagon response to IIH is a general feature of autoimmune diabetes.

Through a process of elimination, we concluded that the primary defects causing this early glucagon impairment in NOD mice are located within the islet itself. For instance, although the brain [33] and the islet alpha cells [34] are glucose-sensitive, the hypoglycaemic stimulus in the diabetic NOD mice was identical to that in the nondiabetic controls. Likewise, similar adrenaline responses to IIH ruled out an impairment of sympathoadrenal activation, such as that found after repeated bouts of hypoglycaemia. Thus, the defects causing the early impairment of the glucagon response to IIH are either loss of islet sympathetic nerves, loss of islet endocrine cells, or both.

Although the loss of islet beta cells is established in diabetic NOD mice [21], it was not known until this study whether or not this model of autoimmune diabetes also has a loss of islet nerves. Using NPY as a marker, we demonstrated here a loss of sympathetic nerves within the islets of NOD mice that had been diabetic for only 3 weeks. Because activation of islet sympathetic nerves stimulates glucagon secretion [35], this islet nerve loss has the potential to remove a significant alpha cell stimulator that is both activated during hypoglycaemia [36] and contributes to the glucagon response to IIH in non-diabetic animals [15]. However, the contribution that this nerve loss (eSIN) makes to the impaired glucagon response to IIH in diabetic NOD mice remains to be established. In contrast, there is published evidence that the loss of islet beta cells does contribute to this impairment in diabetic humans [37] and in rat models of diabetes $[6,38]$; therefore, it is likely to contribute in the diabetic NOD mouse. We have not ruled out a generalised alpha cell defect in these cyclophosphamide-treated, 3 week diabetic NOD mice, due either to alpha cell loss or islet inflammation secondary to invasive insulitis. 


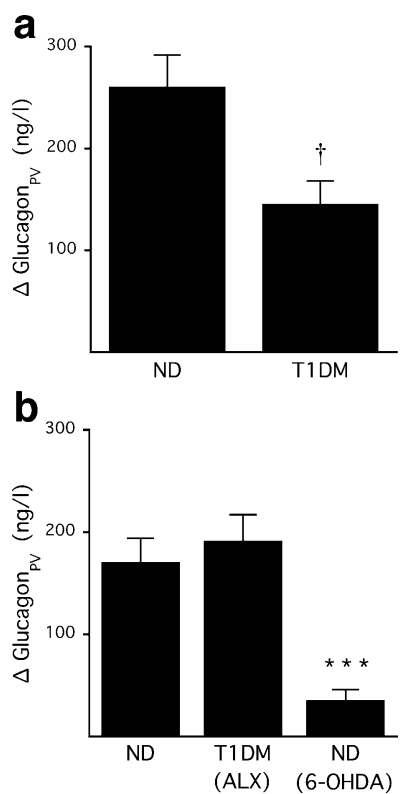

Fig. 6 Impaired glucagon response to sympathetic neural activation. a Portal vein $(\mathrm{PV})$ glucagon response $(\Delta)$ to sympathetic neural activation induced by tyramine in NOD mice with naturally occurring autoimmune diabetes (T1DM, type 1 diabetes mellitus; duration of diabetes, 3 weeks) and their age- and sex-matched non-diabetic controls (ND). b Glucagon responses $(\Delta)$ to tyramine in NOR mice with non-autoimmune alloxan (ALX) diabetes (duration of diabetes, 3 weeks), in non-diabetic NOR mice pretreated with 6hydroxydopamine (6-OHDA) and in their age- and sex-matched controls. Significant difference compared with non-diabetic controls: ${ }^{\dagger} p<0.005, * * * p<0.0001$

Rather than investigate the relative contributions of islet endocrine cell dysfunction and eSIN to the impaired glucagon response to IIH in diabetic NOD mice, our subsequent studies focused on the mechanism of eSIN. Our current data, coupled with previous reports, rule out three non-autoimmune mechanisms for eSIN. First, although chronic hyperglycaemia causes diabetic autonomic neuropathy [39], it is not a cause of eSIN because the islet sympathetic nerve area was not reduced by the 5 weeks of chronic hyperglycaemia that accompanied alloxan diabetes in NOR mice. Second, eSIN is not an artefact of reduced islet size because their islet size was not reduced significantly after even 5 weeks of NOD diabetes. In addition, alloxan treatment of NOR mice, which did markedly reduce islet size, did not reduce islet sympathetic nerve area. Third, eSIN is not due to beta cell loss per se because high-dose alloxan, which produced severe insulin-requiring diabetes, did not cause a loss of islet sympathetic nerves. These exclusions leave the lymphocytic attack of the islet, or the related islet inflammation, as the most probable mechanism for the loss of islet sympathetic nerves.

Indeed, there tended to be more invasive insulitis in the islets of NOD mice with 3 weeks of cyclophosphamideinduced diabetes when compared with their non-diabetic NOD controls; however, these non-diabetic controls had a substantial amount of invasive insulitis of their own. We reasoned that this moderate level of invasive insulitis should also destroy some islet nerves even in the absence of diabetes. Indeed, we found that the more heavily infiltrated islets of non-diabetic control mice had significantly fewer islet nerves. Therefore, invasive insulitis, in the absence of diabetic hyperglycaemia, was associated with a significant loss of islet sympathetic nerves.

We next tested whether increased duration of NOD diabetes exacerbates the islet nerve loss and, if so, whether it is associated with greater invasive insulitis. Indeed, there was more nerve loss at 5 weeks of naturally occurring diabetes compared with that seen after only 3 weeks. This progressive nerve loss contrasts with the islet nerve loss of diabetic BB rats, which was similar when compared between 1-3 weeks and 1-3 months of diabetes [17]. Likewise, islet infiltration progressed with increasing duration of naturally occurring NOD diabetes, reaching a significant increase at 5 weeks duration. We examined the relation between insulitis and islet sympathetic nerve area across all our mice and found a highly significant, negative relationship. When analysed across groups, the correlation suggested that invasive insulitis is the major determinant of the loss of islet sympathetic nerves in the NOD mouse, a factor not examined in our studies of the BB rat [17]. However, to definitively prove this suggestion, an interventional experiment was necessary.

Our intervention was the administration of CFA. CFA given to NOD mice is known to block dendritic cells and Tlymphocytes, but not macrophages, from invading the islet [40]. Because blocking the invasive insulitis by CFA treatment prevented the loss of islet sympathetic nerves, we conclude that the invading lymphocytes are required for this nerve loss. Further studies are needed to determine whether this lymphocyte-mediated nerve loss is due to cytotoxic Tlymphocytes targeting an autoantigen on sympathetic nerve terminals, to the release of neurotoxic cytokines from invading lymphocytes [41] or to the release of anti-sympathetic neurotropins [42] from invading B-lymphocytes [43].

While the loss of sympathetic nerves from the islets of diabetic NOD mice was clear, the functional impact of that loss was not. Therefore, we tested for impaired glucagon responses to selective, sympathetic activation in diabetic NOD mice. We and others have used tyramine to selectively activate peripheral sympathetic nerves [44-46]. Our diabetic and non-diabetic NOD mice had similar portal venous noradrenaline responses to tyramine, confirming both equal activation of gut sympathetic nerves and a negligible contribution of islet sympathetic nerves to portal venous noradrenaline levels. However, the glucagon response to tyramine was significantly impaired in diabetic NOD mice, a finding consistent with loss of islet sympathetic nerves. Indeed, the major loss of sympathetic 
nerves induced by 6-hydroxydopamine pretreatment of non-diabetic NOR mice nearly abolished the glucagon response to tyramine.

Neither beta cell loss nor hyperglycaemia was an additional contributor to the impaired glucagon response to tyramine because that response was normal in alloxan diabetic NOR mice. Our NOD diabetic mice that received tyramine did not lose alpha cells, ruling out another potential contributor. However, studies showing preservation of the glucagon response to another glucagon secretagogue, one whose action is independent of sympathetic nerves, would be needed to rule out a generalised alpha cell dysfunction, secondary to the islet inflammation.

Acknowledgements We thank E. Kirk for managing the NOD mouse colony; E. Haines for glucagon, catecholamine and glucose measurements; A. Zavosh for glucagon measurements; and H. Chang for glucose measurements. This work was supported by the Medical Research Service of the Department of Veterans Affairs and by National Institutes of Health Grants R01 DK 50,154; P30 DK 17,047; R01 DK 40,963 and R01 DK 63,159.

Duality of interest The authors declare that there is no duality of interest associated with this manuscript.

\section{References}

1. Bolli G, de Feo P, Compagnucci P et al (1983) Abnormal glucose counterregulation in insulin-dependent diabetes mellitus: interaction of anti-insulin antibodies and impaired glucagon and epinephrine secretion. Diabetes 32:134-141

2. Fanelli CG, Epifano L, Rambotti AM et al (1993) Meticulous prevention of hypoglycemia normalizes the glycemic thresholds and magnitude of most of neuroendocrine responses to, symptoms of, and cognitive function during hypoglycemia in intensively treated patients with short-term IDDM. Diabetes 42:1683-1689

3. Dagogo-Jack S, Rattarasarn C, Cryer PE (1994) Reversal of hypoglycemia unawareness, but not defective glucose counterregulation, in IDDM. Diabetes 43:1426-1434

4. Heller SR, Cryer PE (1991) Reduced neuroendocrine and symptomatic responses to subsequent hypoglycemia after 1 episode of hypoglycemia in nondiabetic humans. Diabetes 40:223-226

5. Patel D (1983) Effect of prolonged insulin treatment on blunted plasma catecholamine and glucagon increase during insulin hypoglycemia in streptozotocin diabetic rats. Metabolism 32:377-382

6. Zhou H, Tran PO, Yang S et al (2004) Regulation of alpha-cell function by the beta-cell during hypoglycemia in Wistar rats: the "switch-off" hypothesis. Diabetes 53:1482-1487

7. Patel DG (1983) Lack of glucagon response to hypoglycemia in long-term experimental diabetic rats. Diabetes 32:55-60

8. Hertelendy ZI, Patel DG, Skau KA (1992) Progressive and concurrent deterioration of vagus-stimulated and hypoglycemiainduced glucagon secretion in streptozotocin-diabetic rats. Acta Endocrinol (Copenh) 126:80-84

9. Ahren B, Stern J, Gingerich R, Curry D, Havel P (1995) Glucagon secretory response to hypoglycaemia, adrenaline and carbachol in streptozotocin-diabetic rats. Acta Physiol Scand 155:215-221

10. Taborsky GJ Jr, Ahren B, Havel PJ (1998) Autonomic mediation of glucagon secretion during hypoglycemia: implications for impaired alpha-cell responses in type 1 diabetes. Diabetes 47:995-1005

11. Shi ZQ, Rastogi KS, Lekas M, Efendic S, Drucker DJ, Vranic M (1996) Glucagon response to hypoglycemia is improved by insulin-independent restoration of normoglycemia in diabetic rats. Endocrinology 137:3193-3199

12. Carra M, Brambilla P, Meschi F et al (1990) Pancreatic polypeptide secretion after insulin infusion and protein meal in juvenile type 1 diabetic subjects. Acta Diabetol Lat 27:165-171

13. Davis M, Mellman M, Friedman S, Chang CJ, Shamoon H (1994) Recovery of epinephrine response but not hypoglycemic symptom threshold after intensive therapy in type 1 diabetes. Am J Med 97:535-542

14. White NH, Gingerich RL, Levandoski LA, Cryer PE, Santiago JV (1985) Plasma pancreatic polypeptide response to insulin-induced hypoglycemia as a marker for defective glucose counterregulation in insulin-dependent diabetes mellitus. Diabetes 34:870-875

15. Havel PJ, Mundinger TO, Taborsky GJ Jr (1996) Pancreatic sympathetic nerves contribute to increased glucagon secretion during severe hypoglycemia in dogs. Am J Physiol 270:E20-E26

16. Seemayer TA, Oligny LL, Tannenbaum GS, Goldman H, Colle E (1980) Animal model of human disease. Diabetes mellitus. Am J Pathol 101:485-488

17. Mei Q, Mundinger TO, Lernmark A, Taborsky GJ Jr (2002) Early, selective, and marked loss of sympathetic nerves from the islets of BioBreeder diabetic rats. Diabetes 51:2997-3002

18. Mundinger TO, Mei Q, Figlewicz DP, Lernmark A, Taborsky GJ Jr (2003) Impaired glucagon response to sympathetic nerve stimulation in the BB diabetic rat: effect of early sympathetic islet neuropathy. Am J Physiol Endocrinol Metab 285:E1047-E1054

19. Yoshida K, Kikutani H (2000) Genetic and immunological basis of autoimmune diabetes in the NOD mouse. Rev Immunogenet $2: 140-146$

20. Sosenko JM, Palmer JP, Greenbaum CJ et al (2006) Patterns of metabolic progression to type 1 diabetes in the Diabetes Prevention Trial-Type 1. Diabetes Care 29:643-649

21. Reddy S, Pathipati P, Bai Y, Robinson E, Ross JM (2005) Histopathological changes in insulin, glucagon and somatostatin cells in the islets of NOD mice during cyclophosphamideaccelerated diabetes: a combined immunohistochemical and histochemical study. J Mol Histol 36:289-300

22. Kano Y, Kanatsuna T, Nakamura N et al (1986) Defect of the firstphase insulin secretion to glucose stimulation in the perfused pancreas of the nonobese diabetic (NOD) mouse. Diabetes 35:486-490

23. Foulis AK, Stewart JA (1984) The pancreas in recent-onset type 1 (insulin-dependent) diabetes mellitus: insulin content of islets, insulitis and associated changes in the exocrine acinar tissue. Diabetologia 26:456-461

24. DCCT (1987) Effects of age, duration and treatment of insulindependent diabetes mellitus on residual beta-cell function: observations during eligibility testing for the Diabetes Control and Complications Trial (DCCT). The DCCT Research Group. J Clin Endocrinol Metab 65:30-36

25. Reddy S, Chai RC, Rodrigues JA, Hsu TH, Robinson E (2008) Presence of residual beta cells and co-existing islet autoimmunity in the NOD mouse during longstanding diabetes: a combined histochemical and immunohistochemical study. J Mol Histol 39:25-36

26. Ott PA, Anderson MR, Tary-Lehmann M, Lehmann PV (2005) $\mathrm{CD} 4+\mathrm{CD} 25+$ regulatory $\mathrm{T}$ cells control the progression from periinsulitis to destructive insulitis in murine autoimmune diabetes. Cell Immunol 235:1-11

27. Qin H, Sadelain M, Hitchon C, Lauzon J, Singh B (1993) Complete Freund's adjuvant-induced -T cells prevent the development and adoptive transfer of diabetes in nonobese diabetic mice. J Immunol 150:2072-2080 
28. Jacobson L, Ansari T, Potts J, McGuinness OP (2006) Glucocorticoiddeficient corticotropin-releasing hormone knockout mice maintain glucose requirements but not autonomic responses during repeated hypoglycemia. Am J Physiol Endocrinol Metab 291:E15-E22

29. Fisher SJ, Bruning JC, Lannon S, Kahn CR (2005) Insulin signaling in the central nervous system is critical for the normal sympathoadrenal response to hypoglycemia. Diabetes 54:1447-1451

30. Jacobs RJ, Dziura J, Morgen JP, Shulman GI, Sherwin RS (1996) Time course of the defective alpha-cell response to hypoglycemia in diabetic BB rats. Metabolism 45:1422-1426

31. Gerich J, Langlois M, Noacco C, Karam J, Forsham P (1973) Lack of glucagon response to hypoglycemia in diabetes: evidence for an intrinsic pancreatic alpha cell defect. Science 182:171-173

32. Amiel SA, Simonson DC, Tamborlane WV, DeFronzo RA, Sherwin RS (1987) Rate of glucose fall does not affect counterregulatory hormone responses to hypoglycemia in normal and diabetic humans. Diabetes 36:518-522

33. Sherwin RS (2008) Bringing light to the dark side of insulin: a journey across the blood-brain barrier. Diabetes 57:2259-2268

34. Weir GC, Knowlton SD, Atkins RF, McKennan KX, Martin DB (1976) Glucagon secretion from the perfused pancreas of streptozotocin-treated rats. Diabetes 25:275-282

35. Marliss EB, Girardier L, Seydoux J et al (1973) Glucagon release induced by pancreatic nerve stimulation in the dog. J Clin Invest 52:1246-1259

36. Havel PJ, Veith RC, Dunning BE, Taborsky GJ Jr (1988) Pancreatic noradrenergic nerves are activated by neuroglucopenia but not hypotension or hypoxia in the dog: evidence for stressspecific and regionally-selective activation of the sympathetic nervous system. J Clin Invest 82:1538-1545

37. Raju B, Cryer PE (2005) Loss of the decrement in intraislet insulin plausibly explains loss of the glucagon response to hypoglycemia in insulin-deficient diabetes: documentation of the intraislet insulin hypothesis in humans. Diabetes 54:757-764

38. Zhou H, Zhang T, Oseid E, Harmon J, Tonooka N, Robertson RP (2007) Reversal of defective glucagon responses to hypoglycemia in insulin-dependent autoimmune diabetic BB rats. Endocrinology 148:2863-2869

39. Brownlee M (2001) Biochemistry and molecular cell biology of diabetic complications. Nature 414:813-820

40. Qu P, Ji RC, Shimoda H, Miura M, Kato S (2004) Study on pancreatic lymphatics in nonobese diabetic mouse with prevention of insulitis and diabetes by adjuvant immunotherapy. Anat Rec A Discov Mol Cell Evol Biol 281:1326-1336

41. Zhu J, Bai XF, Mix E, Link H (1997) Cytokine dichotomy in peripheral nervous system influences the outcome of experimental allergic neuritis: dynamics of mRNA expression for IL-1 beta, IL6, IL-10, IL-12, TNF-alpha, TNF-beta, and cytolysin. Clin Immunol Immunopathol 84:85-94

42. Krizsan-Agbas D, Pedchenko T, Hasan W, Smith PG (2003) Oestrogen regulates sympathetic neurite outgrowth by modulating brain derived neurotrophic factor synthesis and release by the rodent uterus. Eur J Neurosci 18:2760-2768

43. Edling A, Nanavati T, Johnson J, Tuohy V (2004) Human and murine lymphocyte neurotrophin expression is confined to B cells. J Neurosci Res 77:709-717

44. Jacob G, Costa F, Shannon JR et al (2000) The neuropathic postural tachycardia syndrome. N Engl J Med 343:1008-1014

45. Vo PA, Tomlinson DR (1997) Effects of adrenergic stimulation on sciatic nerve blood flow in diabetic and control rats. Eur $\mathrm{J}$ Pharmacol 329:147-152

46. Mundinger TO, Cummings DE, Taborsky GJ Jr (2006) Direct stimulation of ghrelin secretion by sympathetic nerves. Endocrinology 147:2893-2901 